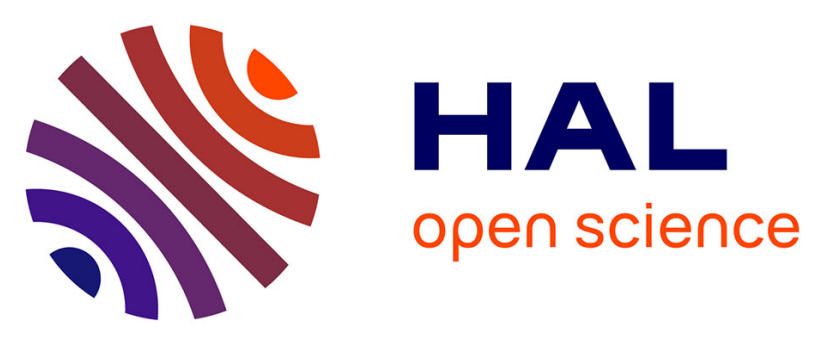

\title{
The case of Gaël
}

Guy Brousseau, Virginia M. Warfield

\section{- To cite this version:}

Guy Brousseau, Virginia M. Warfield. The case of Gaël. Journal of Mathematical Behavior, 1999, 18 (1), pp.7-52. 10.1016/S0732-3123(99)00020-6 . hal-00696270

\section{HAL Id: hal-00696270 https://hal.science/hal-00696270}

Submitted on 8 Jun 2012

HAL is a multi-disciplinary open access archive for the deposit and dissemination of scientific research documents, whether they are published or not. The documents may come from teaching and research institutions in France or abroad, or from public or private research centers.
L'archive ouverte pluridisciplinaire HAL, est destinée au dépôt et à la diffusion de documents scientifiques de niveau recherche, publiés ou non, émanant des établissements d'enseignement et de recherche français ou étrangers, des laboratoires publics ou privés. 


\title{
The CASE of GAEL ${ }^{\mathrm{i}}$
}

Guy Brousseau, University of Bordeaux

Jacques Pérès

Virginia M. Warfield, University of Washington

\begin{abstract}
The Theory of Didactical Situations has had a central position in French mathematics education research since the early seventies. A major component of this theory is the didactical contract, a completely implicit but highly powerful aspect of the relationship between teacher and student. In this article we relate the series of tutorial sessions which provoked the original formulation of that theory, and in which the theory was validated by its first application.

Gaël was an intelligent child who was failing exclusively in mathematics. He was one of nine cases studied between 1980 and 1985 (at the Bordeaux COREM ${ }^{\mathrm{ii}}$ ). After observing him in class and offering him various learning situations, both didactical and adidactical, we arrived at the hypothesis that Gaël was implementing an strategy of avoidance of the "conflict of knowing" which we characterized as "hysteroid type avoidance", whereas the others exhibited "obsessional type avoidance" (note that these behaviors should not be confused with the psychiatric categories of the same name, which are serious personality disorders.) It was possible to offer psychological explanations for this behavior, but they did not provide the means for correcting the avoidance, and they focused the interest of the researchers on a characteristic of the child or on his competencies, rather than remaining at the level of his behavior and the conditions which provoked it or which might modify it. This behavior demonstrated the
\end{abstract}


refusal, conscious or not, of the child to accept his share of the decision-making responsibilities in a didactical situation and hence to learn while working with an adult.

It made it possible for the experimenters to explore and understand the constraints of the didactical situation, interpreted as a "didactical contract". It is the simulacrum of a contract, an illusion, intangible and necessarily broken, but a fiction which is necessary in order for the two protagonists, the teacher and the learner, to engage in and carry out the didactical dialectic. The didactical means to get a student to enter into such a contract is devolution. It is not a pedagogical device, because it depends in an essential way on the content. It consists of putting the student into a relationship with a milieu from which the teacher is able to exclude herself, at least partially (adidactical situation). The mechanism implemented was devised to engage Gaël progressively but explicitly in a challenge in which the teacher could be "on the student's side."

This situation subsequently revealed itself to be one of the fundamental situations of subtraction.

This article is one of a matched pair in French and English resulting from a threeway collaboration between Guy Brousseau, Nadine Brousseau and Virginia Warfield. It was launched by the desire of the latter to make available to the English-speaking community an article written by Guy Brousseau in 1981. The resulting discussions produced so many modifications and clarifications that the three undertook to make the improved version available also in French. The process provided splendid evidence that 
differences in linguistic and cultural perspective can be a source of considerable intellectual enrichment.

\section{INTRODUCTION to the English Language Version}

(Warfield)

One of the most widely known articles in the "gray literature" of the field of Didactique is the "Cas de Gaël" (the Case of Gaël), by Guy Brousseau, which originally appeared in 1981. It is the Cas de Gaël which, modified, clarified and translated, is the main content of the current article. In order to explain its importance, we will start with the background of the article, and of its author.

Guy Brousseau began his career in the classroom, teaching, experimenting, observing and writing reams of notes. He then spent the decade of the Sixties simultaneously extending his knowledge of mathematics and using the knowledge he had gained in the classroom as a basis for interpreting the works of Diènes, Piaget and others

(or possibly vice versa). This heady combination produced, in 1970, the Theory of Situations, which was to generate the entire field of Didactique des Mathématiques. A brief description of the theory appears in the general introduction below.

But it was not a theory intended to be merely decorative. Brousseau was determined to see it tested and expanded by means of serious experimentation. To that end, he threw himself into an effort being made by a group of mathematicians in and 
around Bordeaux, as part of a general movement led by A. Lichnérowicz to persuade the Ministry of Education to provide the means to modernize the teaching of mathematics. These means consisted of I.R.E.M.'s (Institutes for Research in Mathematics Education), at which university professors and in-service teachers could carry out research combining their respective fields of expertise. Their labors paid off, and the I.R.E.M. of Bordeaux was duly founded-one of the first such in France. Brousseau joined it, with the task of arranging for the carrying out of his projects.

For that, Brousseau further persuaded the university and ministry to set up the Ecole Michelet, which combines the properties of being a regular public elementary school and of being designed for controlled, observed experimentation in the teaching of mathematics.

During the same period, Brousseau carried out a study on the learning processes of a number of students in "selective" mathematical difficulty - that is, students who in other academic areas were at a reasonable level, but who were for some reason failing in their mathematics. The specific situation of the study is described below, but it seems worthwhile to point out one of the many ways in which this case resonates with more familiar contexts. In the course of my first reading of the original article, I was haunted by a feeling that I had met up with Gaël in some other circumstance, under some other name. Eventually it dawned on me that he could have stepped right off the pages of John Holt's "Why Children Fail". He influences his instructor with exactly the sweet submissiveness as Ruth. In her case, though, whether consciously or unconsciously, she 
leads the tutor into reducing the content of the problem practically to nothing. This is, in fact, the method of Gaël's friend Cyrille, but his manner of accomplishing it is more that of Emily, whose inability to sustain uncertainty turns her into what Holt calls an "answergrabber". Gaël and Cyrille may have been small, French schoolboys, but they represent an international legion!

\section{General Introduction}

(Brousseau)

Gaël, aged 8 1/2, was one of nine children in selective (mathematical) difficulties whom I tried to help by a small number of clinical, didactical tutorial sessions between 1976 and 1983. I prepared the sessions, recorded them, transcribed them and analyzed them with my friend Jacques Pérèz, a psychologist, and a small team of collaborators and students. The subjects of the studies were

1. the type of intervention which might improve the mathematical behavior and knowledge of the children

2. the characteristics which distinguished these children from others (Did they have some particular way of behaving or of failing? Did they fail on the same questions as other children in difficulties?)

3. the knowledge they lacked. 
They attracted attention to two forms of avoidance of learning in a school situation: Gaël's "hysteroid" form and the more frequent and more visible obsessional form.

These studies were carried out in parallel with other research, all of it directed towards developing and testing the Theory of Situations which was in the process of being elaborated. The Theory of Situations is based on the idea that human knowledge is manifested in its rôle in the interactions between systems: actors, milieu and institutions. To each piece of knowledge it should be possible to associate a limited number of specific types of interaction whose proper development requires that knowledge, or even causes it to develop. The characteristic situations for pieces of mathematical knowledge can be studied and even modeled within the framework of mathematics itself, which sometimes makes it possible to use computation to predict their evolution.

The teaching of a notion consists thus of setting up its situations and carrying out interactions in which the learner can take part. It is, itself, an interaction. We have shown that this interaction is also largely specific to the knowledge being taught but that it takes a form - a didactical situation-necessarily different from the non-didactical forms in which knowledge is used. This result changes the entire approach to mathematics education and the education of teachers. 
The theoretical and experimental study of didactical situations and their practical consequences is a long story in which le Cas de Gaël has held an important place. There are three major reasons for this importance:

1. The situation proposed for Gaël tends to replace constructive (in the mathematical sense) definitions of subtraction, in which the student reproduces an algorithm which is shown to him and which gives the desired result, by an "algebraic" definition, in which a number must be found to satisfy some condition (a difference is what must be added to some number to find some other number: $39+\diamond=52$ ). It is the prototype of the situations with which we explored the possibilities of replacing arithmetic by algebra as early as possible in primary school.

2. In proposing to replace the construction of a term by the understanding of a relation and the search for an object satisfying it, the situation brought sharply into evidence the paradoxical conditions of all didactical situations which make it simultaneously necessary and impossible to maintain an effective didactical contract. This concept had its birth in the course of the experiment.

3. Finally, this experiment brought to light the relationships and irreducible differences between the didactical, the psycho-cognitive and the psycho-affective approach to a teaching situation.

\section{THE CASE OF GAEL}

\section{FIRST SESSION}




\subsection{The session itself. Red Cars}

The tutor launches the first session with the question: "Do you know what things you had trouble with this week and what things you really knew how to do?" He gets only evasive replies. Gaël takes out his notebook and the two examine the week's work. They eventually choose the following problem, which Gaël had done wrong:

In a parking lot there are 57 cars. 24 of the cars are red. Find the number of cars in the parking lot which are not red.

Gaël thinks a moment, then announces: "I am going to do what I learned from the teacher." He writes $57+24$ in a column and gets $81-$ exactly what he had done during the week. It appears that Gaël has mastered the operation of addition, which he has to carry out frequently, but he never once asks himself when it is supposed to be used. Instead, he covers himself with the authority of the teacher to justify an automatic use of the operation. He pays no attention whatever to the corrections made in class.

The tutor comments, without too much emphasis, as if it were general remark, that you need to know when to do addition or subtraction or something else; then, in an encouraging tone, he suggests that Gaël draw the cars "but not all of them, because that would take too much time." 
Gaël draws a rectangle and writes 57 in the middle.

T: (the tutor) asks: "Is that all of the cars?"

G: "It's all of the cars that aren't red."

T: "Only the cars that aren't red?"

G: "It's all of the cars and they aren't red."

The tutor could have continued with "Then where are the red cars?", but it was obvious that the child did not have a correct representation of the situation. Putting him into a formal contradiction would serve only to embarrass him.

T: "If the number of cars changed, that might change the operation?"

G: "Yes!!"

It is clear that what Gaël calls "operation" is the triple of numbers, not "addition" as opposed to "subtraction". The tutor had hoped that Gaël might have in mind the question: add or subtract? In that case, he would have tried to find out if the child was able to construct an equivalent problem using small numbers for which the drawing could have been done quickly. The fact that Gale doesn't understand the question obviates the possibility of pursuing this line. The tutor asks Gaël to draw the 57 cars, one by one. Gaël starts off trying hard to make pictures that really look like cars, but at the instigation of the tutor, switches to making marks. The tutor has him make them in lines of twenty. 
.T: "Have you drawn all of the cars in the parking lot?"

G: "No"

T: “The directions were 'In a parking lot there are 57 cars. Draw the parking lot.' Are there 57 cars in this parking lot?"

G: "Yes"

T: "Are all the cars the problem was talking about in this parking lot?"

G: "No, there are some red cars, too."

The tutor points out that he needs to pay careful attention to the text, because there is a period after the "57 cars". Gaël then admits that the red cars are in the lot, but thinks he still needs to draw them because they don't show up in his design.

Here one can see that he has difficulty in envisaging that there is only one set of cars, with two properties: being in the parking lot and being red. For him, the second property necessitates a second set, and even though he admits that the second set also has the first property, he can't yet conceive of its being a part of the original set. Is it because he hasn't analyzed the statement of the problem, or because he can't use the operation of inclusion?

The tutor explains that the 24 red ones are part of "these" cards - the original 57-and Gaël should paint them red on his design. At this stage, Gaël's actions are totally guided by the tutor. Together they verify that the drawing corresponds to the 
problem statement, then Gaël has to find all of the cars which are not red. He counts 31 of them. The tutor asks:

T: "If I tell you it's the wrong answer, do you think I am right?"

G: "I don't know."

T: "What would you do to find out if I am right?"

G: "I'd count again."

And he gets 33 .

T: "So, which is right, 31 or 33 ? What can we do to find out?"

G: "We have to count."

T: "There's no other method?"

No answer.

His drawing having been sufficiently concrete and having made it possible for him to give an answer, Gaël doesn't try to use, or think of using, an operation to verify his answer, because he can count as often as he likes. His drawing is a sure support to which he can refer, whereas an operation calls for certain abstract mechanisms and includes a reversibility which Gaël seems not to have acquired, to know how to use subtraction to find the two terms of the addition.

Gaël does another recount: “33”. 
The tutor circles the red cars,

\section{[Insert Figure 1]}

gets Gaël to observe that there are thus 24 red and 33 non-red and asks:

T: "So how many cars are there?"

G "I do 24 and then 33 ?"

Gaël sets up an addition problem: $24+33=57$

T: "So have you got the answer they were calling for? Can you answer the question the problem asked?"

G: "No"

For most children, the answer required is supposed to be the result of an operation, and the solution is to be found at a specific spot in the arrangement of what was written. This habit is an obstacle when it comes to identifying the answer in an equation regarded as a relation. 
T: "Yes you can! You wrote what they asked you to write."

$\mathrm{G}$ is astonished. At the request of the tutor he rereads the problem.

T: "How many cars are there that are not red?"

With the aid of the drawing, he gets Gaël to say that there are only 33. He asks him how he found them and Gaël answers "by calculating", then corrects it to "by

drawing." The tutor explains that calculating "is so we can find the answer without having to draw everything" and Gaël acknowledges that that is what he doesn't know how to do.

The tutor decides to get Gaël to use the symbolic representation in use in his classroom, with the idea that it will help him. Gaël draws the parking area, puts in the red cars, then the others, and then attaches labels:

[Insert Figure 2]

T: "If I count the red ones I get...?"

G: “”24”

T: "And if I go on and count the rest I get...?"

G: "57" 
The tutor writes

$+\ldots$

57

set up so that Gaël will not use subtraction to find 33 and instead will try to find the number which can be added to 24 to get 57 , which he does easily.

In the course of this first phase certain characteristics begin to appear which are common among students in difficulties: difficulty in making sense of the question asked and in working out strategies to check the answer; recourse to recipes, etc.

To clarify the nature of Gaël's difficulties and to insure that he will not once again draw a set of automatic conclusions from this sequence, the tutor poses two similar problems.

The first has the cars forming two disjoint sets clearly identified in the statement of the problem. All that is needed is to add their numbers to get the total, which Gaël does swiftly.

The other one is comparable to the initial problem, with 8 cars of which 3 are red.

Gaël draws a circle with 8 cars

then does the drawing over to include the 3 reds : 


\section{[Insert Figure 3]}

and when asked how many are not red he replies "11". Once again he applies to the authority of the operation he knows, without stopping to think. By drawing the cars and coloring three, as before, he does get the answer.

It should be explained that in Gaël's class subtraction had not been introduced as the only way to find a difference. Addition with a gap was frequently used. This procedure tends to force the child out of the automatic formal association of a mathematical operation with a material operation (+ if I add, - if I take away) and to transfer the focus to the set which is being counted and its relationship with the givens of the problem.

\subsection{Test of the quantification of inclusion}

The incomprehension Gaël demonstrated in this exercise could simply have had psychogenetic origins: the child might be too young to carry out the necessary reasoning. Solving a problem like this, which involves considering the whole and the part simultaneously so as to compare them, assumes a type of logical operation which Piaget showed to have a complex character. The quantification of inclusion required for the understanding of the car problem is, in fact, not constructed by a child until around the age of seven or eight. It was therefore necessary to assure ourselves that Gaël had an 
operational scheme. We decided on the spot to give him the colored balls test. This wellknown test, used by Piaget, consists of presenting the child with eight wooden beads, of which five are red and three green. The subject has to judge whether there are more wooden beads or red beads and to justify his answer. Gaël succeeded with the test ${ }^{\mathrm{iii}}$, justifying us in our thinking that the repeated failures of the child in the use of the relation of inclusions did not result from gaps in access to logico-mathematical structures.

\subsection{Test of commutativity}

We then decided to present Gaël with another operational test used by Gréco in his research on the genesis of the operation of commutativity.

The child is presented with a set of rods set up as follows:

[Insert Figure 4]

It is clear to the child that $\mathrm{A}+\mathrm{B}=\mathrm{C}$

Rod B is then put in place of $\operatorname{rod} A$ and the child is asked to make a mark where the end of A would come to if A were put after B:

[Insert Figure 5] 
Gaël says immediately : "The end is going to be right where it was before!" and makes a mark in line with the end of $\mathrm{C}$

\section{[Insert Figure 6]}

The response characterizes a child who has achieved the operational stage, which does not surprise us as all, given the age of the child and his success with the preceding test ${ }^{\mathrm{iv}}$. What is, on the other hand, interesting, and can provide us with some information, is the attitude of Gaël when we cast some doubt on his judgment by objections along the lines of "but a kid told me a few minutes ago that the end is short of that", etc. Gaël instantly backs off of his assertions:

G: "That might be right..."

T: "What do you think, exactly?"

G: "I don't know!"

This type of conduct on this test characterizes children whom Gréco situates in an intermediate (pre-operational) stage, where the structures of the subject are still under construction, so that the compensations are incomplete and fragile. This cannot be the 
case with Gaël. It would seem that without any doubt, his sudden absence of conviction in the face of a simple counter-proposition has to do with his general attitude towards others around him when his own knowledge is put into play. The conviction which, for Piaget, reveals the functioning of an operational structure disappears here without its being possible to blame it on a fragility of logical constructions. It is the result, we think, rather of his manner of being with those around him.

\subsection{Analysis of the first session}

Among the questions arising from Gaël's behavior there was one which had to be checked out swiftly. All mathematical activity is supported by operational schemes of the subject which, according to Piaget, are not learned in the strict sense, but constructed in the course of development. In the case of the red and non-red cars, we could see that it was absolutely necessary to assure ourselves that Gaël really did have the operational structure of inclusion.

With the results from the test with the wooden beads, we knew at least that Gaël's repeated failures to understand the problem could not be explained by gaps at the level of his logico-mathematical structures. Manifestly, he had the operational schemes necessary to solve the problem proposed. How then to explain his behavior in the course of the session?

The response is guaranteed not to be simple from the moment that one takes as an object the relationship between a single subject whose current relationship with the 
world is the result of a lot of past history and a didactical situation which itself is quite complex.

In this perspective, Gréco's test gives us something to start with. The immediate cause for surprise is Gaël's complete incapacity to maintain his conviction in the face of anyone else's contradiction. One counter-proposition is enough to produce doubt right at the momnent when to all appearances he was feeling completely convinced. A characteristic of the child thus appeared which we had already encountered in the course of a psychological examination on a more general front: flight from any possible confrontation and the avoidance of conflict at any cost by taking refuge in a position of dependence and submission.

It seemed to us that this might well have an impact on Gaël's relationship with mathematical knowledge. In the area of knowledge, there is, in effect, an attitude where dependence offers the non-negligible benefit of a security: knowledge is always somebody else's knowledge which one has only to appropriate; thus, one eliminates the risk of having oneself put into question in a debate about truth. There is no need to offer any reason for what one takes for truth other than the invocation of the authority to whom one refers. (Gaël says "what I was taught", "what the teacher says I have to do")

But the price of this attitude is an incapacity to conceive of a process of construction where knowledge might be the result of a confrontation with reality, and in which the subject becomes the author of his own knowledge. Mathematical knowledge thus risks being simply a ritualized activity of reproducing models. 
Situations of the type that students normally encounter in class tend to present certain closed characteristics. For example, the teacher poses a question and all of the students are supposed to find the answer-the same one-so that the minute one student publicly produces the answer, all of the others stop looking for it. Furthermore, it is the teacher who pronounces the solution correct so that each student has only one chance per problem to attempt to find the solution. This way, every one of these situations functions as a test and learning has to happen elsewhere-from the correction and the explanations that accompany it, for example - by means other than trying things out and observing the effects of one's own decisions. Eventually, and partly in consequence, the solution frequently can't be envisaged unless the child already has a representation of the situation which permits him to bring out the cognitive objects in question, the more so since the verification of the validity of the answer and the explanations of the teacher call on this same representation, on the already achieved knowledge which produced the answer. Otherwise stated, this learning situation gives no opportunity to make or attempt a decision - thus to learn-except to those who already know most of it. In these situations, the student can only acquire the right representation of the situation by making the connection between similar tests by a convenient sort of reinforcement by association.

Situations of this type are not helpful it all in getting students like Gaël to modify their relationship with either the givens of the problem or objects of knowledge. 
To augment and enrich a student's relationship with the situation, one classic procedure consists of asking them to represent - to draw - the elements that are involved. That is what was done in this session, and it showed that making the correct drawing required exactly the representation that the student lacked. It seems reasonably clear that although this schematization may perhaps produce progress in an existing representation, it cannot create one.

On the contrary, the repetition of problem-situations which the teacher expects to be the key to comprehension tends to put the student in a situation of slightly anxious, passive waiting, where the activities have a ritual and almost magical character. This reaction is visible all through the first session: "I am going to do what the teacher taught me..."; when he adds he recites carefully "I put this here, I carry this,...the tens column..." and marks off each step. His representations are more or less analogues of reality, and he tries to draw things that really look like cars. But the fact that he stays very close to the concrete, far from producing the required meaning for the operation, seems to be taken by the child as a means of keeping his distance from any reasoning about the objects.

When the tutor asks him: "Have you drawn the red ones?" he answers "No, only the black ones", and it is true that he hasn't drawn the red ones (in red). He focuses on his drawing without making it play the role of a representation for checking on the information in the problem statement. And when he is asked to color over the marks representing red cars with a red crayon he forgets how many there were and the tutor has to stop him at 25 . In general, numbers are of very secondary importance to him. He says 
50 and he counts 31 , then 33 , he forgets...he acknowledges his errors with good graceand detachment.

A classical approach in dealing with children in difficulty consists of identifying the errors or mistakes that they make, and if they are repeated, interpreting them as anomalies in the development of the child, or gaps in their acquisitions which need to be remedied because "they are going to make the child unable to progress in mathematics."

For example, we observed that Gaël frequently wrote $\square$ for 5 , or wrote 12 for 21 which could be interpreted as a lack of spatial structure or even trouble with spatiotemporal perception. In the same way, Gaël's difficulties in connecting his drawing with the text of the problem could be classified as malfunctionings of the symbolic function.

This classical analysis leads to a search for remedies in the form of exercises "of the same type" in the sense of these functions: exercises in spatial structure, etc. This is the opposite of the teacher's search, which is for exercises "of the same type" in the sense of the same mathematical subject treated from the same didactical point of view: writing numbers, dictation of numbers, subtraction problems, etc. In this sense, the first appears therapeutic relative to the second, The approach we are trying here is very different: it's a matter of working at the level of the learning situations and manipulating their characteristics so as to obtain the desired changes in attitude. For that we will use a "theory of situations" which we discuss elsewhere. This theory studies, as its principal object, the conditions of the milieu which make the behavior of the subjects and the manifestation of knowledge necessary and plausible. 
Gaël's relationship with knowledge-at least the knowledge involved in the classroom-is strictly superficial. His habit of avoiding problems and keeping his distance lead to stereotypical actions of a purely "didactical" nature - that is, centered entirely on the relationship with the teacher without mobilizing any of the assimilation schemes which, for all that, he does have at his disposition. Gaël accommodates himself to a set of institutionalized relations which on his side call forth only rituals which do not engage him at all. It seems possible, thus, that all of Gaël's attitude during this first session is the consequence of an accord between the habitual didactical situation in the class as he perceives it and his defensive relationship with knowledge of which we spoke earlier.

One cannot maintain the position that the didactical situation that Gaël habitually encounters is the sole cause of his failures in mathematics. If it were, why would other children, no better armed than he on the cognitive front, succeed? All we can think is that he finds this situation a convenient one in that it lets him escape the effort of constructing knowledge. And he can escape it all the better for his manner of dealing with adults - his own particular social attitude made up of sweetness and submission, which defuses all criticism, leaving him forearmed against any form of conflict with the teacher.

Why does this cause failure? Because, if the habitual didactical situations permit learning in the closed conditions we described above, it is because the debate on knowledge is replaced by another type of debate-one which deals with the learning 
student. Learning badly, not knowing, making thus and such an error are all forms of running afoul of the will of the teacher, of being in conflict with him. From there out, the student can only escape conflict and all the resulting difficulties by building something which will take the place of knowledge and of learning.

Now Gaël, we would say, escapes this debate in the extent that he disarms all conflict by a total absence of aggressiveness. In student-centered debate, the conflict effectively feeds on itself: the teacher's aggressiveness calls for a habitual response of agressiveness from the student, which in turn feeds the aggressiveness of the teacher, etc., with the subject having no way out except by producing the expected results. Gaël, for his part, doesn't join this game. His profoundly submissive attitude disarms all hostility ("He's always ready to acknowledge his mistakes and he's really sorry" says the teacher.)

\subsection{Projects for the next session}

The set of analyses we have been able to make leads us to envisage how we are going to handle the second session. The essential issue will be to introduce a rupture in Gaël's conceptions of a didactical situation by offering him a situation which will require of him anticipation, prediction and the undertaking of responsibility, that is, that he invest (in the sense of an army of occupation) the object of knowledge. To do that, we are going to stay on the same mathematical subject and propose to him what we call a situation of action. 
Only if it becomes apparent that Gaël cannot enter into this type of relationship with knowledge will we search for other means of intervening.

\subsection{Commentary: Topaze and the recalcitrant student}

In order to make a certain number of didactical concepts available, we are going to start with a commentary-possibly a slightly heavy-handed one-on a famous example of a teaching situation: the first scene of Marcel Pagnol's play, "Topaze”.

[Translator's note: in order to avoid jeopardizing Brousseau's excellent commentary, we have chosen to translate the passage word for word. The reader is therefore in dire need of the following information: in French the words for lamb ("mouton") and lambs ("moutons") are pronounced identically, as are the words for was (“était") and were (étaient")]

Topaze is dictating while pacing the room:

“Some lambs...some lambs...were safe in a park...in a park." [He leans over the shoulder of the Student and starts again] Some lambs...some lambsss...[the student looks up, startled] "See here, my friend, make an effort. I'm saying lambsss. Were" [he 
repeats with great finesse] "we-re. That means there was not just one lamb. There were several lambsss.”

The student looks at him, lost. ${ }^{\mathrm{v}}$

In this ironic and touching scene, Pagnol brings out with almost cruel relevance several common characteristics of this kind of situation.

The teacher wants to obtain a certain behavior from his student-here the correct spelling, under dictation, of the word "lambs". This behavior signifies that the student has correctly interpreted a situation-in this case, the sentence - that he has recognized a problem, at least implicitly — does lambs have an s or not? - and that he has resolved it by the application of a piece of knowledge, possibly a practical one-in this case, the rule for pluralizing nouns.

In this case, the student doesn't solve the spelling problem which has been set him, and Topaze can't bring himself to accept the situation. The problem is that the expected behavior provides not just a piece of information about the state of the student, but also the material on which the rest of the teacher's activities are based. The mistakes in the text produced are too numerous and too trivial, which makes it impossible to base any reasonable "lesson" on it. For the teacher, this subordinate error in accord needs to be eliminated right away. But he can't resolve himself either to give the student the correct answer flat out or to put on explicit pressure (for example by giving a warning like "Pay attention!") He therefore transforms the spelling test into a mini-situation of 
learning. And what does he do? He tries to obtain the same behavior but by changing the problem. His second reading completely changes the situation-a student conscious of the dilemma: "singular or plural?" would have found the answer by solving a simple phonetics problem. Obviously, his behavior would then have had neither the same meaning nor the same value.

Alas, the student doesn't take up this new game. He emphasizes by his startled air that he doesn't understand why his teacher is expressing himself in such an extravagant manner. And Topaze is constrained to explain his poor ruse and justify himself: "One lamb...several lambsss". He simultaneously provides the open choice between the possibilities-i.e., the contents of a lesson undoubtedly reproduced a hundred times-and the solution in the current case. The student finally registers the problem and its solution at the same time. He has contented himself with identifying what the teacher wants through the transparent veil of a didactical disguise.

We can see thus how Topaze proposes a sequence of situations all attempting to produce the same behavior, but giving it completely different meanings, which are progressively less and less rich, and cost the student less and less of an investment and of knowledge. It's a kind of negotiation: Topaze tries to obtain the student's behavior "at the best price" , that is, with the situation which will have the most meaning for the student, and everything shows that the student is content to wait until Topaze proposes the contract which will require the least effort of him. 
In these conditions, of what could the hoped-for learning consist? The teacher ends up choosing a situation which enables the student's system of knowledge to furnish the desired response. The correct behavior can be produced by the repertoire which he has already acquired, but which has nothing to do with the new knowledge that was the goal. The hope that learning will happen with this strategy is based on the belief that repetition of relevant questions associated with answers which are correct but obtained with inadequate knowledge will cause the correct knowledge to arise. This is impossible even if the scale of the decreasingly difficult questions being posed to the student until he furnishes the right answer is graduated and frequently repeated. Between an inadequate repertoire and an adequate repertoire there is a leap consisting of exactly the knowledge to be acquired. 


\section{SECOND SESSION}

\subsection{Session and observations}

The tutor presents Gaël with the goal of the session: it's to teach him the things he didn't know how to do the last time, which a child his age should be able to do and which he, too, will soon know how to do. But this teaching will take the form of a game.

This prologue has no impact whatever. Apparently the word "game" is frequently used to introduce simple exercises.

The materials consist of circles and triangles, large and small. The tutor has Gaël count the number of pieces, of which there are 52 , and tells him to write the number on a sheet of paper. Afterwards, for assurance that there really are 52 pieces, the tutor recounts , pointing out that he is using stacks of ten: a pile of 26 triangles, then a stack of 10 circles $(=36)$ then another $(=46)$ then a stack of 6 circles: total 52 pieces.

Once the pieces are counted, they are put in a bag and the bag is closed, and the game consists of remembering what was in the bag.

The tutor asks the child if he knows what there was, to which he replies: "triangles", then hesitates and adds: "squares" (there were none)... "circles". Then at the request of the tutor he draws 


\title{
[Insert Figure 7]
}

\author{
"We counted how many pieces?" asks the tutor. \\ "26" \\ “26?" \\ "No, 52" \\ "What did I count 26 of?"
}

Gaël no longer remembers. He thinks a long time, but has to be reminded that it was triangles.

Next the tutor explains that they are going to play a guessing game:

"What do you think I am going to ask you?"

"How many circles there are."

"Do you remember how many there were?"

"No"

"Then we can look in the bag if you don't know. But before we take them out and look at them, we have to make a bet. Do you know what that means?"

Gaël says he sometimes bets a franc against his father that he will be the first to reach the bottom of the swimming pool. 
The game, then, consists of betting how many circles there are and writing down the number. Then if the verification confirms that number, the bet is won.

First bet: Gaël states that there are 10 circles.

Verification: There are 26. Gaël smiles and agrees with the tutor that he has lost his bet.

Starting with this first round, and this will be confirmed in the following rounds, it is noticeable that the number 10 plays a special role for Gaël. He has registered the fact that the tutor arranged the pieces in stacks of 10, and this might perhaps have contributed to his first choice, but as we will see further on, this is not the only reason.

The tutor proposes that henceforth the bet will be for a caramel. Gaël smiles.

After this first failure, they decide to start again. But Gaël has already forgotten the goal of the session and doesn't remember any more what they counted first and believes that it was just the circles. The tutor therefore has him write again the number of pieces -52 . Then he has him count the large red circles: 19. He verifies the latter by again making a stack of 10 and a stack of 9, then they put everything in the bag and close it.

Gaël writes on his sheet of paper:

[Insert Figure 8] 
"What do we need to do?", the tutor asks.

"Find out how many triangles there are."

"Yes . And were there any squares?"

"No. Just triangles and circles."

When the child said the first time that there were squares, he was probably speaking at random, not having inspected the different pieces, busy as he was with counting, and having trouble backing off enough to think about what he was counting.)

In any case, this first scene confirms Gaël's difficulty keeping track of the givens, and even of the task at hand.

This time, the task is going to be to find out how many are not "big circles", that is, the number of little circles and triangles taken at the same time.

Gaël thinks a bit: "Triangles...there were lots of them" and makes a random guess of 50 .

He writes $52 \quad 19 \quad 50$ 
The tutor gets him to confirm that it's a matter of counting triangles and little circles and draws underneath the numbers the things that according to Gaël they represent:

\section{[Insert 9]}

He then sums the situation up by saying that there are 50 on one side and if the big circles are added there will be 52, then asks if he wants to stick with his bet. Gaël takes it back, because he observes that to get from 50 to 52 there wouldn't be many big circles, "there are just 2".

He corrects his choice and announces 30, then writes

[Insert Figure 10]

To verify, he takes the objects out of the bag, counts that there are 33 and exclaims: "I was really close!"

It is important to remark that he is still really at the level of trial and error, and each time he is trying his luck, but little by little efforts at reasoning are beginning to appear. 
Here, certainly, the tutor, cashing in on favorable circumstances, introduced a fundamental method of verifying the values being guessed and thus provoked a contradiction between what the child predicted and what he observed and a first step in taking charge of the situation. There was a risk that this departure from a state of encouraging neutrality would throw Gaël back into his dependence on the adult and back to looking for his answers in the adult's questions. But this observation was made in the form of a summary of what Gaël had just said and done-a summary which the adult addressed to himself, without even asking any questions. The observation was so clear to the child that he didn't spot any intention directed toward him. The tutor took care to accept the next proposal without comment.

“That's better", says the tutor, "but you still haven't won. Shall we play again?"

Gaël accepts - one can tell that he would really like to win. Again he writes 52, counts the small circles (7) puts all of the pieces in the bag and is supposed to guess the number of things that are not small circles. .

He thinks out loud: “There are $52 \ldots$ since there are 7 small circles...". He laughs because he is trying to add 7 to something to get 52 and he has a feeling he is on the right track. He writes 42 (note that that is $52-10$ ) and makes the bet. But first he verifies by using his fingers to add $42+7$, observes his mistake, crosses out 42 , writes 49 (the number most recently arrived at $-42+7)$. He can go no further and he makes the bet. 
All the counters are taken out of the bag, the tutor has him stack them in tens, and there are 45 (which are not small circles). Gaël crosses out 49 and puts 45, which gives $\begin{array}{lllll}52 & 7 & 42 & 49 & 45\end{array}$

The tutor remarks: "There's a trick - but it has to be found." For the first time, the tutor indicates that the results to be expected are determined by the givens.

The number of givens that Gaël pays attention to has suddenly increased a lot, and he can only handle the cycle once through: choice, anticipatory verification, rejection, new choice. The bet is a period when the tension relaxes - a pleasant moment of pretending to think, hesitating a little, then deciding and solemnly shaking hands with the tutor. Then with a bit of slightly feverish excitement the sack is opened, the count is reckoned, the resulting number is compared with the prediction, while the tutor looks on dubiously with furrowed brow, simultaneously sorry, encouraging and comically powerless. The bets have to remain reasonably dense to maintain the child's pleasure - they are the real source of gratification.

The fourth bet again has a prize of a (hypothetical) caramel bar. This time the little triangles are counted (13) but then put into another bag, into which the bag with the other pieces is also put.

[Insert Figure 11] 
As before, Gaël mutters to himself as he calculates: "52 there, 13 there". He counts on his fingers, slows down at 10 , then picks back up again and says " 42 ". But after a long re-count he corrects it to " 41 "

To verify, the tutor empties the first bag - that is, his dumps the 13 triangles on the table and puts the other bag to the side, closed.

"If you have won", he says "there will be 41 in there [pointing to the other bag] and counting all of them there will be...?" " $52 "$

Starting with 41, Gaël then counts the 13 little triangles: “ $42,43, \ldots$, and gets 54.

Since the bag hasn't been opened, he still has the right to change his bet, and the tutor lets him search.

Gaël was forgetting the method of verification (or possibly he was trying to count backwards, which requires simultaneously counting what is being taken away and the result: $1-51,2-50,3-49,-$ but that's improbable.)

The tutor opportunely again suggested the method of verification and helped him to get it working, but Gaël didn't take this as a new set of directions, because he could 
think of the method as already agreed on, and his principal problem, at that moment, was to count correctly and to have a strategy for choosing the numbers to try.

Gaël smiles, seems to remember something and counts on his fingers from 13 to 52.

But in the course of doing so, he stops because he has lost track of how many he has counted so far, and tries another method:

"Oh! There are 13 there. I take away 10 and that leaves 3 and in the other one there are ...45...there are 52. I take away 10 , that leaves $40 \ldots 5.45$ !” $(42+3$, maybe?)

"Let's verify!" Again the number turns out to be wrong and the tutor suggests trying another number. He chooses 40 , adds 13 (by counting all of the triangles one by one) and seeing himself so close to the goal he exclaims: "Aha! I have a proof already!" but which one?

Next he tries 31, The tutor writes all of the numbers which do not work, and beside them the result of adding 13, giving successively:

$\begin{array}{ll}44 & 54 \\ 40 & 53 \\ 31 & 44\end{array}$




$\begin{array}{ll}43 & 56 \\ 33 & 46 \\ 42 & 55 \\ 34 & 47\end{array}$

Now the method of verification is really working. The fact of being able to count the objects in the known part has differentiated the functions of the three numbers: the solution number - the one that is being bet on, and from which the count starts - the number of objects in the known part which are to be counted (rather than added), and the total number of objects which is the final number the count should get to. It is doubtful that this algorithm has been acquired as a general solution for subtraction problems, but it will be useful in exploring relations invariant under translation and from there it will permit an approach to a method of solution and of sorting out several problems in numeration and the primary structure of the natural numbers. Above all, it permits an investment of the terms of the relationship that is to be understood.

Let us observe the strategy. Everything would have worked out fine if Gaël were completely in control of counting backwards (or subtraction of 1), because he started with 41 which gives too big a result. He tries another method-a correct one-but he doesn't have it at all under control at the moment and tries 45 , which puts him further from the goal, so he corrects it and tries 40 (the only number that he can easily put in the neighborhood of 41 that is smaller than 41). It seems reasonable to think that he is using as a principle of correction : "if a bigger number puts me further away, then a smaller 
number will put me closer" which implies that he postulates that the application is monotone. And 40 produces an exciting result: he is really close. It seems reasonable to think that for Gaël the result confirms the validity of his intuition: "the proof" , and on top of that that he sees that he has to take 1 from 40 . Which would imply that he registers that a correction of 1 in the choice changes the total by 1 in the same direction. The theorem will work for 2 in just a moment. It probably wouldn't work for 8 or 10 . But Gaël doesn't know how to find the number before 40 - he subtracts 10 and adds a unit: 31-failure. Return to the previous strategy: bounding. Gaël increases the lower numbers $-31 . .33 \ldots 34-$ and decreases the upper ones $-43 \ldots 42 \ldots$ Even if the upper ones stay above 40 this could work...where has he gotten to?

This time he successfully uses the theorem of conservation of differences in a numerical translation (the difference between the two total results is equal to the difference between between the numbers tried.) But he only succeeds because he doesn't have to get past a multiple of ten.

The first success of the exercise is celebrated as it should be with a free chat, in the course of which Gaël announces that he would like to play the bag game again and learn to find the number - to figure it out. The tutor offers it "right away" and Gaël says "Yes". "With small numbers, then, because you're tired."

There are 7 pieces, some of them triangles and some rectangles. Gaël counts 3 triangles and puts everything in the bag. 
"How many rectangles are there?", asks the tutor.

“7"

"No. 7 altogether..."

"How many rectangles are there? There are 3!" , Gaël declares.

"You want to bet?"

Gaël hesitates, wonders a bit.

"You can draw them to figure it out..."

He draws 3 triangles, then before drawing the rectangles announces "Four".

The tutor tells him to draw them, but he can't remember the shape any more, and has to feel them through the bag to remind himself. He re-counts after making the rectangles.

This last episode in the observation is important, because it shows, brought out by fatigue, Gaël's difficulties in associating a number with what it represents. He did observe the different classes of objects and he did count the objects, but he seems to run into a barrier in getting from one notion to the other. To a large extent it is this laborious passage which causes his hesitations: he often gets stuck on the classification side, then when he finds way to count them, he no longer knows what his point of departure was. 
One source of difficulties may be the proximity of the numbers-here 3 and 4 . Thus we took care in preparing the materials for the session to provide cardinals of fairly different sizes: $45-7$, then 39 - 13 (except that for the initial phase we had $26-26$, and that was a mistake).

\subsection{Observations on Gaël's difficulties}

This session brought out some of Gaël's long-standing difficulties with numeration:

- difficulty making a durable assignment of a cardinal to a collection

- difficulty managing several numbers at the same time, especially if they are invisible, but even if they are not.

- In numeration, also difficulty with the "privileged role" of the number 10 , which crops up frequently inappropriately as a fetish number. On this subject one can make the following remark: the privileged role played by the number 10 in numeration, in calculation of sums with carrying or differences with borrowing or multiplication, must seem to a child who is not up on things to be essentially magic.

- Difficulty especially in getting past the multiples of 10 in counting backwards and thus in ordering the names of the numbers. 
Obviously, we also observed some other difficulties, such as for instance the perfectly natural one of sustaining his attention at times, but we do not intend to discuss those here.

\subsection{Effects of the session}

Are we now able to answer some of the questions we asked ourselves before the session?

- For a start, it seems perfectly clear that Gaël is completely capable of entering into an action situation. He accepted progressively the rules of the game which consisted of taking charge of an objective and of the means of verifying by himself that it had been achieved, of hazarding solutions and of checking them against the state of the milieu. He took over progressively the search for a good answer, rejecting contradictions and inadequate solutions himself. He took pleasure in the game of predicting and verifying even when he didn't win.

- He engaged voluntarily in going the route of anticipation. This last point is very important for more than one reason:

-Anticipation is the first step towards creation of a theory and passage to an experimental basis: the subject gives up the procedural mode, with only direct interactions with the milieu, and the trial and error method and sets himself at a distance from his actions. This reflexive attitude leads him to a declarative mode. 
-Anticipation rests on the existence of at least an implicit model, true or false, on which it is based and the expression of which permits it to be put to the test. Here the model is the relationship: number known + number tried $=52$, and it seems sure enough to Gaël to permit him a rapid simulation of the experiment (it is never put to the question, at least as regards its validity.)

It is interesting to note that Gaël did indeed master the steps of anticipation: we wanted him to interest himself in the material nature of the givens of the problem statement; we produced the collections in question with a bizarre and captivating ceremony so as to augment the affective, perceptive and sensorial weight of the search for a solution. Now, investment in application is in a way antagonistic to investment in action, in the sense that it assumes at least a provisional refusal. Here, Gaël is to renounce the pleasures of action, of decision, of betting, of the game, to replace them by calculations and simulations. But in any case, it should be remarked that anticipation inherits to a certain extent the motivation associated with the situation that it simulates. Gaël experiments with his predictions with the little shiver of pleasure recalling the one he feels at the moment of betting.

Finally, the successive consideration of several possible predictions in the course of a single bet, and the fact of writing them permits the examination at the same time of diverse choices and consequently the choice of a strategy based on the structure of this universe of possibilities. The passage from a "contingent" prediction where the subject 
doesn't conceive of the situation as having any other issue than the one envisaged to a prediction of possibilities is an indispensable step towards the emergence of a "prediction" of the necessary where the issue is predicted from among others for reasons of logic or mathematics or something different but theoretical.

Gaël is thus capable of entering into all these phases of the dialectic of action, of producing and checking implicit models, even though, as we shall see below, the efficacy is still a bit weak. He probably accomplished this activity naturally, which would explain the normal development he can be observed to have had. His stereotypical attitudes which can be observed in class and his tendency to search for easy answers by interpreting the suggestions of the adult are thus an effect of his manner of using the didactical situation.

We were able to see here that this situation is not ineluctable. The choice of an appropriate situation did indeed produce the rupture we envisaged, with the efforts predicted. To be sure, this "accidental" rupture has not yet changed Gaël, nor his relationship with knowledge. It was partly obtained by making use of his major fault: the desire to seduce the adult and maintain affective and playful relations with him. This game with knowledge needs to be regularly installed and to persist in ordinary didactical circumstances. In fact, there is no question of asking Gaël's teacher to modify her pedagogic methods which are working for lots of other students and which no doubt offer many similar occasions which Gaël simply doesn't grasp. 


\subsection{Projects}

What we must do thus is to study the means of engaging Gaël in this route and of giving him the taste and the means of seeing to his learning.

There is also a lot left to do to get him to master situations of subtraction and give them some sense.

Gaël has no problem whatever in envisaging the sets present. He manages without difficulty to isolate the triangles and the "non-triangles" and include them in the starting collection, whether or not the "non-triangles" have a clear common property (squares and circles...)

One could suppose that it would suffice for him to associate with these set operations the corresponding numerical operations inverse to each other, addition and subtraction.

Certain didactical methods thus consist of illustrating one or another case by a set of examples and problems, sufficient to suggest the field of operation of each one. In these methods the procedures of calculation, the implicit model and the theory never change in the course of learning; it's a question of associating an already made mathematical structure with some situations assumed understood or understandable and it is these situations which constitute the meaning of mathematical operations. 
These methods are based on conceptions of significance and learning which are fairly old and much discussed. With a lot of simplification, they can be summed up as follows:

The set of realizations of a piece of knowledge or a theory, that is, the objective situations in which it turns out to be valid, constitute what it signifies. To give a meaning to a structure means to find some applications for it-places where it can be used.

A piece of theoretical knowledge, to be learned, must be constituted from knowledge already known and by a discourse or by logical (or mathematical or scientific or rational,...) means which are themselves already known, or in fact "learned" directly ready made (in the sense of committing it to memory), for example as an algorithm. Giving a meaning in the latter case comes down to making it correspond to problems or situations where it is realized, that is, where the objects it talks about are present or the relationships it envisages are true. Teaching will consist of producing conditions to associate the two after one or the other has been memorized.

Generally, in lots of cases the process of learning leads back, even though with diverse justifications, to conditioning: whether one is starting with the theory and looking for its applications or starting with cases and hoping to produce an abstraction to the structure or both. 
This association does not work out too well, because the interpretation of the situation doesn't get produced unless the complete theoretical schema is known and inversely the theory cannot be well understood if it has neither a justification nor any explicative or descriptive function. The miraculous and a-historical adaptation of the theory to the hoped-for practices is an obstacle to partial learning. The theory must be learned in its definitive and correct form, adapted to complex, advanced examples to which it is to be applied. The best one can do is to chop the theory into simple bits and look for simplified situations where these bits by themselves take on the value of theory or application - always a perfectly adapted one. But whether one chops or not, it always comes down to needing to associate two pieces of knowledge which have already been “achieved" learned or constituted independently of each other.

To palliate the difficulties of learning this association (unmotivated for the student and reposing entirely on didactical decision) the teacher can refine the method by introducing illustrations (manipulations, schemas, mnemotechnical discourses) designed to emphasize the association, but not producing any advance in either of the two.

Here, one could "teach" Gaël the elements he lacks: make a plan, identify in a given situation an appropriate plan, solidify subtraction by the repetition of manipulations and the association of an appropriate discourse: "I take away, I re-group, ..." 
On the other hand, what we are trying to do here is to get Gaël to construct and learn a theory using a different process, an historical one.

We are going to consider a different component of the meaning of subtraction. ${ }^{\text {vi vii }}$

For example, to take 5 from 57 one can count backwards, possibly counting on fingers in order to stop at five: $\begin{array}{lllll}56 & 55 & 54 & 53 & 52\end{array}$

$\begin{array}{lllll}1 & 2 & 3 & 4 & 5\end{array}$

To be sure, it is more complicated as a procedure, but the child can keep a tight connection between the representatives of the numbers and the names of the numbers being counted off. It is thus more economical (or more primitive as far as theoretical knowledge goes). In any case, it is impracticable if it's a question of subtracting 39 from 57.

One can maintain on the theoretical front that if $\mathrm{a}+\mathrm{b}=\mathrm{c}$ it is logically equivalent to take $\mathrm{a}$ or $\mathrm{b}$ from $\mathrm{c}$, but it is clearly not true in the present case: to take 52 from 57 it would be necessary to "invent" another system and count from 52 to 57 counting on the $\begin{array}{lllllll}\text { fingers or otherwise the missing elements: } & 52 & 53 & 54 & 55 & 56 & 57\end{array}$

$\begin{array}{lllll}1 & 2 & 3 & 4 & 5\end{array}$

It is well known that the moment the objects are no longer physically present this method breaks down because the student no longer knows whether to "count 1 with the 52 or the 53". Certainly in the classical methods of teaching the teacher made sure always to examine "all the meanings" of differences: what is missing, what is left, what there is too 
much of, or too little of,...etc., but always flatly, as facets of the same piece of knowledge, and without worrying about the adaptation of these points of view, nor about their place in a genesis of communication.

The method Gaël uses here is different and based on a better knowledge of the ordered set of natural numbers and of their orders of magnitude. To find what needs to be added to 39 to get 57 , it consists of taking a number close to the result on which the calculations are simple, for example 20, then making corrections with the aid of the theorem of the conservation of differences:

$39+20=59$, which is 2 more than 57 , so it is enough to add $20-2=18$. This method is much used in mental calculation. Clearly it is not a "method" for Gaël-it can't be put to use whatever the situation that arises, it is not recognized as such and it is not even a piece of knowledge: Gaël would not be able to tell his father what he learned in the second session. A whole process would be needed to turn it into an object of knowledge which is efficient, conscious and well mastered at the theoretical level.

And for all that, this method stumbles over Gaël's old difficulties with numeration. We could well believe that we re seeing here how a defect in the acquisition of an old notion can render impossible an activity which is essential for the acquisition of a new notion. But in fact, no, we are not in the presence of a real situation of the learning of numeration. Though Gaël has little grasp of the situation as an occasion for learning subtraction because he is unaware of the didactical intentions of the tutor and what the object of his didactical desire is, it is clear to him that he is tripping over the 
possibility of counting certain numbers (finding a predecessor to 40). That is what is keeping him from establishing an efficient strategy. No question that when by some other means he finds 39 , that answer is going to take its place also as the answer to "What is the predecessor to 40 ?"

It would be possible to "didactify" this part of the learning: recognize the difficulty, recall the means to surmount it, re-explain, do some exercises in counting backwards, etc.

We are not going to do it. But to point out clearly the didactical character of Gaël's difficulties, we arranged a short sequence of this type at the end of the next session.

To return to a plan for the learning of subtraction, other strategies appear in other conditions (with other numbers) but with the same basic situation: for example, from 39 to $40-1$, from 40 to $50-10,10$ and 1 eleven and from 50 to $57-7 ; 11$ and 7: 18 . This method, the most widespread in mental calculations, is also based on order and decimal numeration. It gets more efficient for larger differences. The standard algorithm can appear as a shortcut for this procedure or as the result of some other reasoning. Learning it could be organized as a frequent presentation of the same didactical situation where the only thing varying was certain conditions favoring the constitution of these strategies. The possibility of replacing one by the other will confer upon them a certain equivalence (from the point of view of meaning), the choice of one or the other depending on its utility or efficacy. These strategies mobilize all the fundamental 
schemas of sums and differences. The order of their apparition constitutes a genesis (good or bad) of the concept and gives them a meaning.

We will not evoke here the processes of formulation, validation or institutionalization which will permit the emergence of subtraction as a theory at the disposition of the child.

In the third session we are going to take up the same situation again.

\section{THIRD SESSION}

\subsection{Session and observations}

The tutor takes up the guessing game from the last session without any modifications: there are 56 pieces which Gaël counts and puts in a bag after having written the number on a sheet of paper. The tutor then takes 10 big circles out of the bag, has Gaël count them, then puts them in another bag along with the first bag. The question is how many pieces there are in the inside little bag.

Gaël thinks a bit, counts to ten and says " 5 !" The tutor shows him the 10 circles, then shakes the other bag and asks if he really believes there are only five in there. Gaël smiles, blinks and shakes his head, acknowledging that he has made a mistake. In fact, 
Gaël has just reproduced his habitual mode of response: he counts to ten-stereotypical behavior - then since he has to give an answer, gives a random one.

The tutor does not accept this response. In class, the teacher cannot make this kind of stubborn demand of every student for every problem.

Gaël then follows up in a mutter: " $56 . .$. then there are $10 \ldots$ (he counts to 40), I'm up to 40 and 10 are taken away,...that makes 40 !' In fact, he hasn't changed procedures, he has just given a more plausible number to live up to the adult's expectations. The fact that the number to subtract is ten, the magic number, may contribute to this disarray.

The tutor then reminds him of the principle of verification of the statements during the last session: "We made a bet and we checked if we were right"...without, of course, saying what operation was used. While he is doing so, the child, smiling, thinks, then exclaims: “46!"

It seems clear that he is sure of his answer. It seems possible that reminding him of the conditions of the situation has been enough to make it possible for him to check his answer and thus to produce a correct one. It also seems possible that Gaël was playing a subtler game, throwing out provisional answers to gain time to think it over, or even simulating his habitual response to tease the instructor. In any case, this scene demonstrates Gaël's need to "decorate the silence". 
T: (slightly jolted by the rapidity of the response) “ How come you're saying that makes $46 ? "$

G: "Because I know that you take 5 from 10 and that makes 4 and that leaves 6 so that makes 46."

T: “!!!”

Doubtless the way to translate this answer is: from 5 tens we subtract one ten (formula backwards), and that leaves 4 . In 56 there are 5 tens and 6 ones; these 6 ones together with the 4 tens give us 46 .

Here Gaël is directly using the resources of numeration to effect his subtraction by the system: $56-10=(50+6)-10=(50-10)+6=40+6=46$. It is true that under these conditions this method gives a simpler procedure than the one which would have been necessary during the preceding session: $52-7=(50+2)-7=(50+2)-(2+5)=$ $(50+2-2)+5=50-5=(40+10)-5=40+(10-5)=45$. And despite that, Gaël is already having trouble formulating his solution.

This difficulty manifests itself in the incapacity to designate the order of the numbers in his statement and by the apparition of an inversion in one of the relations ("take 5 from 10" instead of "take one ten from five tens"). Things often happen as if Gaël worked out the relations in two stages: first the binary relationship and the pair on which it operates, then the ordering of the pair. Likewise, for example, in 21 he first 
grasps the pair, then the ordered pair $(2,1)$; i.e. 2 "gadgets" and 1 "thingey" then, if necessary, the order 2 tens and one unit, i.e., 20 and 1.

After explaining his answer (46), Gaël sets out to verify it. But first the tutor asks if it isn't possible to know how many pieces there are without opening the bag. Gaël's reply: "Oh, no. There is no way of knowing."

The tutor then reminds him of the method used the time before, when they considered that the bag had a certain number of pieces and then added onto this number the number of the pieces spread on the table: if no error had been made, the resulting number was the total number of pieces. Gaël uses this method and figures that in fact, this time he has not made a mistake. To be absolutely sure of the result, they are going to empty the bag and count all of the pieces, after betting, but Gaël says he is not "absolutely sure" of winning.

Each one counts some of the pieces, with the tutor making stacks of 10 pieces. At the point when between them they have counted 40 pieces, Gaël stops and says "Oh, I know I have lost." but the tutor encourages him to continue, and at the end of the count he realizes that he had it right.

An observer might be astonished to note that Gaël has forgotten the thing that constituted the key - the engine for the anticipation the previous time. But we know that one of Gaël's difficulties arises from the fact that he doesn't remember what he did before in mathematics. In addition, the suggestion had been made by the tutor; Gaël 
contented himself with latching onto it to carry out his project of prediction in the most satisfying manner (for the tutor) by submission to the desire of the adult.. He, furthermore, had done nothing to draw the child's attention to the procedure. In the didactical contract, for each of them it was a means, not a piece of knowledge "to be learned". It is thus, in a way, satisfying to observe the "innocuity" of a noninstitutionalized suggestion. If the means of controlling had been "taught" there would have been a danger of seeing it used as a systematic means of finding the answer, and even in the best adapted form of addition with a gap, it would have been a pity and undoubtedly a failure for the creation of meaning.

But on the other hand it is clear that Gaël immediately goes about his business of predicting, betting and verifying. For him, it would be really disappointing "that you can know in advance”. Even the proof is doubtful and Gaël hangs onto his suspense (“Oh, I know I have lost") until the last possible moment.

T: "Do you think you could find it if we did something else?"

G: “Maybe, but I'm not so sure” (Let's not take any risks!)

They take out the little circles (5 of them)and put all the rest in the bag. Gaël agrees that there are still 56 pieces in the bag, and provides the following solution:

“There, I think I've got it! Over there we make 50, and there there are 6 and if you take 5 from 6 that would be those (pointing to the little circles) and then that leaves one, so 51 !" 
In this computation, apparently the child mentally set aside 5 stacks of 10 and saved the 6 "unit" elements from which he was able to pull out 5. But what would he have done if, for instance, there had been 7 little circles?

The tutor has him write the 51 and asks him to prove it without counting.

Gaël: "There are still 5, that never changes."

T: "5 what? 5 tens?"

G: "Yes, that. If you take away 6 , there would be 5 taken away, no if you take away 5 there would only be one left. I put the 5 there (small circles) that leaves one (bag) and 5 there."

The child has given a certain character of immutability to the 5 tens : "That never changes". In 56 there are 50 and 6. If 6 are taken away (from 56) and we take away 5, that leaves 1. Thus he is paying attention to those 6 elements, reassured by the knowledge that nothing needs to happen to the other 50.

The tutor brings him back to the other method of verification, adding 5 to the 51 which are supposed to be in the bag.

T: "What is it we do there, 51 and then...? G: "That's it! I've got it! Since there are 51, we can count and get the same number!" 
He seems really pleased, because he has rediscovered the algorithm from the time before and connected it up with the possibility of proof.

But it appears to be the case that this time he has perceived the didactical intention-by way of the tutor's insistence.

\section{Counting backwards: "Getting past the tens"}

To give Gaël a chance to practice counting backwards, and especially to get past the multiples of ten, the tutor uses the same game.

There are still 56 objects in the bag, but he takes some of them out (one by one, at first) and at a certain moment he says "tok" and the child is supposed to say how many are left in the bag.

To get him to understand the rules of the game, he takes the bag, doesn't take anything out, and says "tok". The child says " 56 ". Then he takes out 1 and says "tok". Gaël hesitates, then says " 55 ". The tutor continues, taking out 2. Gaël makes no mistakes and says 53, but when 3 more are taken out, he says " 40 ". So they bet a caramel, Gaël counts up from 40, adding on the objects outside the bag. Arriving at 46 he says he has won. 
The tutor points out that there were 56, and they start again. When there are 50 pieces in the bag, he takes out 3 , but the child does not appear to follow the action.

(Decidedly, as long as the tens place never changed, from 56 to 50, there was no problem whatever in counting in reverse. The difficulty that completely blocks Gaël is that of getting from one tens place to another.)

Gaël is a little lost, but ultimately discovers the solution and successively designates the last 3 elements, counting : 49,48,47.

The game continues, with a "tok" at 43 which gives him no trouble at all. Then the tutor takes out 3 and Gaël says “39”. He bets, verifies by adding 3 to 39, then says to himself "There aren't 39. What could it be, then?" He counts backwards and finds $40-$ number confirmed by verification.

The game continues thus for a few minutes, but the tutor starts taking out the elements by tens and Gaël has not trouble at all giving the result, ending the session with a success.

\subsection{Summary of the results}


The return of the "game" of the bags with slightly simpler givens permitted Gaël to rediscover the initial schema and produce the expected reasoning. We also discovered difficulties and errors of his that we had already known about. Repetition of situations of this sort would unquestionably permit us to lead him to correct his writing errors, to know numeration well and to give some meaning to subtraction problems - especially since the tutor has managed to develop a pleasant relationship with Gaël. There is no doubt whatever that to please the adult, Gaël will identify what is pleasing to the adult, manifest the expected behavior and simulate the desired acquisitions. This will give him the time to cement the affective relations which do not rest on the didactical contract and break off the ones which might constrain him. But that is exactly the problem: the price of his progress would be the reinforcement of exactly what led to Gaël's failure. Gaël's relationships with certainty show that it would be vain to continue in that direction.

\subsection{Observations and analyses}

Gaël's attitude of avoidance in the face of certainty which is in itself surprising becomes more comprehensible if it is put in relation to everything that particularizes his cognitive process.

From the beginning of the sessions we were struck by this profound tendency of Gaël's to give more or less plausible spontaneous answers. He seemed incapable of suspending his highly impulsive reactions for a time in order to reflect, assemble 
information, and slowly construct the necessary inferences. Briefly, one frequently finds this difficulty in entering into processes which have been made secondary.

What we can assume is that in the absence of a deficit on the operational level, such an attitude has a meaning from the point of view of the subject: through it, he pursues a satisfaction or avoids something displeasing. What this behavior puts at a distance during the learning process is the field of certainty. We remarked earlier on the degree to which he was made uneasy by being made to leave the domain of the possible for that of the necessary.

Fleeing total mastery of the knowledge by avoiding all reasoning in favor of answers given at random is in effect, for Gaël, remaining in the domain of uncertainty. This tendency is so strong that, sure of the result, he still tries, by a genuine denial, to abolish the character of certainly from his reasoning: "Oh, I know I have lost!"

We are therefore facing one of the most delicate points of a didactical intervention of this type. The mathematical failure appears here with its symptomatic significance, that is, it goes back to the total organization of the subject and the current equilibrium of his investments.

From that point, if the intervention takes the aspect of a re-education in the strict sense, aiming at the disappearance of the symptom by putting in operation diverse strategies-helping the child to use reasoning, etc.-one courts the risk of failure; the 
counter-investment of the child will come into play and the tutor will be powerless to make a profound difference in the avoidance conducts of the subject. It is equally possible to bring on compensations of a negative sort to the extent that these attitudes play their role of defense against anxiety.

Should we then adopt a clinical approach aimed at determining the unconscious meaning of the avoidance behaviors which probably translate into Gaël's processes in the domain of mathematics? But such an approach is a particularly uncomfortable one. It would be in the framework of an analytical therapy where all forms of intellectual inhibition turn out to be particularly complex and largely overdetermined symptoms. It is all the more so in the framework of an intervention where material by way of projective tests remains fragmentary and where everything which is a trait of the history of the subject as well as of his intra-familial relations remains for the most part unknown. The only hypotheses with regard to the meaning to give to a symptom would rest entirely on the psychological testing done before the first session. We could. in fact, set up a relationship between the results of the Rorschach and CAT tests and the symptomatic character of Gaël's behavior; the fact of an otherwise well-balanced child showing stupor and profound confusion when faced with certain situations would have led us to the interpretation of an anxiety and strong sense of guilt in the face of curiosity connected with the sexual activity of his parents. One could, and various references in psychoanalytical theory would authorize this, recognize in Gaël's avoidance behavior a latent significance connected with the primitive scene; maintaining uncertainty on the level of progress of the thought process means insuring against the anguish of 
recognizing the sexuality of the parents and confronting the sadistic impulses connected with this knowledge.

But even if this interpretation were true, it would be totally useless to us. Our project has nothing whatever to do with working with the child to elucidate his oedipal conflicts; in a psychotherapeutic field the didactical project disappears.

We will therefore restrict ourselves to the domain of the learning of mathematics, but we will consider the mental functioning which we have noted in its relations with the global organization, and figure it into the economic equilibrium of the child. It is not a matter of teaching the child to reason, but of giving him, in the context of the mathematical activities which we are about to discuss, the occasion to reinvest this function.

\subsection{Projects of intervention-Situations to present to the student.}

What are the didactical means that we know and that permit reasoning to function? For the moment its not a question of their content or of their methods, but of their motivation and especially of their control by conviction.

Technically, the student's conviction about proof manifests, confirms and strengthens itself in the four major types of didactical situation, in a different form specific to each: in situations of action, conviction is a affirmed by the confidence of the 
subject in his anticipations. In situations of formulation, the fact of communicating or expressing an idea doesn't necessarily imply a high degree of confidence about it. But precisely what formulation does is to produce an objectivation which plays an essential rôle in the elaboration of conviction. The resulting distance between what is said and what is thought, between a proposition and its implicit truth value, between what is explicitly predicted and what happens, raises the issue of the conviction of the speaker.

The situations in which judgments and proofs are expressed and tested are situations of validation. Part of the convention of this situation is that the subjects exchange opinions about a fact and engage themselves in it. In general, the situations of this nature which we propose set up a proponent and an opponent, both of whom are students, in such a way that they elaborate a system of proof - a theory-founded on intimate conviction and not on authority. The search for truth is a demanding activity which the searcher needs to maintain strongly enough to refuse to be convinced by anything other than personal judgment while nonetheless never refusing to examine any other argument. It must resist authority, seduction, rhetoric, intimidation, social convention, etc. And when it becomes clear that one's opinion is false, it is also necessary to be able to repent, retract and again resist the same difficulties. Difficulties which are legitimate, and which tend to the establishment of reasonably stable truths of which the persons who profess them take account by a sort of personal engagement. Practicing situations of proof or validation permits the subject to construct an interior interlocutor with whom he can simulate debates along the lines he has learned. 
In situations of institutionalization of knowledge, contrary to the preceding, personal conviction is supported, shaken or supplanted by reference to a norm exterior to the subject. His conviction becomes simply a founded adhesion.

In the "problem-solving situations" in class in which we had been told that Gaël participated well and had some bright ideas Gaël can say whatever passes through his head because he has confidence that the teacher will pull out what he wants. Gaël can say things which he "sees" as true without having to affirm that they are. This attitude may be encouaged or even provokd by the group Socratic maieutique methods often used in classrooms.

What are the situations appropriate in the case of Gaël, and which ones can be offered to him?

A classic method would consist of "exploiting" the situation of action we created in sessions two and three, that is, of pushing Gaël to take part, formulate declarations, affirm them, retract them, in a relationship dual to the adult's. The tutor would pull a moral out of each action of Gaël's or have him pull one. For instance, he could repeat the betting situations and insist : "You have to be certain! Are you sure?..." We know that this method cannot succeed.

On the other hand, the tutor, being alone with Gaël, has no way of organizing genuine situations of validation in which the child is supposed to state his convictions to 
an equal. He has to simulate them - and this perhaps might be valuable in that a certain amount of identifying with the tutor might help Gaël out of his "baby" rôle. But there is a danger in that his tendency to stay in a superficial and playful relationship with the adult could destroy any possibility of a debate about knowledge. The playful attitudes consciously used by the tutor risk being "recovered" to reproduce the fundamental dilemma pointed out above.

The tutor therefore needs to accomplish a new modification of the "didactical contract" , reintroducing some demands. In fact, it is to be hoped that a sequence of ruptures can be introduced; in alternation, the tutor could present himself as a partner, an accomplice in a game, or else as an examiner who expects something of him and who says what. It seems evident in any case that the object of the teaching needs to stay hidden to avoid immediate adherence and the submissive behavior we have talked about.

We will come back to the game the tutor needs to give himself up to in order to increase and vary Gaël's positions about certainty and uncertainty. But already, if one returns to the betting game, one might possibly escape the recovery we alluded to without demanding a change of attitude from the tutor: by multiplying the bets and the number of givens present. That way, even if Gaël takes some calculations as opportunities to evade the demands of certainty, it's a good bet that he would not do them all wrong, if his knowledge permits. 
As far as content goes, it would be useful to continue the study of numeration, the more so in that the natural follow-up of the process engaged in with regard to subtraction would lead to the construction and use of a system of symbolization of the quantities present.. We will analyze the situations chosen from this point of view after presenting them.

In the case of Gaël, what position could this partner occupy? We know how much Gaël is dependent on affective climate, to what point his attitude is determined by the other's. An attitude of excessive affective neutrality will send him right back to the stereotypical reactions of false intellectual activity; too great a connivance will permit him a playful attitude where he can behave childishly. It is essential to find the right distance. What the tutor is aiming for is the right alloy of complicity, where the mediation of knowledge and its own demands constantly intervene.

\section{FOURTH SESSION}

\subsection{Support}

The tutor, as planned, starts off with an attitude which is a bit less neutral as regards the mathematical content, and a bit more didactical, though always encouraging. He is going to put on a little pressure. He and Gaël go over the exercises of the week from class. A notable one is an addition: 
Gaël says: " $9+8,17 ;+6=23$. I write the 2 and carry the $3 . "$

“Aha! I see what you did!” says the tutor. Gaël spots it too, unless it's that he deduces it on the basis that if it's not this solution it must be the other one, and he corrects it on the spot.

He finishes up the operation and writes the result, 343, writing the 4 backwards, which the tutor makes him correct by comparing it with the way he himself writes it

He observes that the mistakes Gel has made are mostly related to numeration and the transformations connected with it.

\section{Estimation Game}

The tutor proposes to Gaël that they go back to the estimation game. In preparation, they spread on the table 10 red pieces, 10 green ones, 9 blue ones and 6 yellow ones. On paper, the child therefore writes these numbers arranged as follows

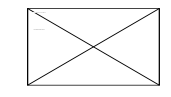


He puts them all in a bag. The tutor checks that he remembers correctly how many of each color there are, then explains how the game is going to go" Gaël is going to take a bunch of objects out of the bag and his job is to figure out how many of each color are left.

\section{First try:}

Gaël takes out a double handful of elements, : 4 green, 2 yellow and 1 blue, and tries to determine the number of green objects left, which he manages very well by counting backwards. The tutor than has him write down the result: 6 and write the name of the color so as to remember what it's about. Same process for the yellows, but when it comes to the reds he hesitates: did he start with 9 or 10 ? He opts for 9 , all because he thinks there were 6 blues. The tutor suggests that he verify by recounting the objects and that he write, so as not to forget:

9 blue

10 green

10 red

6 yellow

They put everything back in the bag and start again.

Here, clearly, Gaël is continuously under the control of the tutor, who intervenes frequently and makes decisions for him, but he keeps trying to get back to the game situation, seeming to want to get out of this didactical relationship. 
The game aspect remains apparent, in spite of everything, even though the operations predominate and the playful activities themselves are put off a little: each time around Gaël has to anticipate four different things.

The game of estimations has exactly the same structure as the previous game, but the givens are ordered quadruples and the answers likewise: for example, on the first try he is supposed to carry out:

$(9 ; 10 ; 6 ; 10)-(1 ; 0 ; 2 ; 4)=(8 ; 10 ; 4 ; 6)$

For the child, the operation looks like a sequence of three subtractions, but Gaël has to keep the quantities in his memory by category: blue, red, yellow, green.

Relative to the previous game, this augmentation of complexity (compensated for in part by the choice of small numbers) will rapidly produce a problem with keeping the operations straight, and thus with keeping track of the given representations.

But these are only "introductory" games. They are there in order to introduce symbolic representations gradually into the scene in conditions which will give them a determined meaning, but it is assumed that these representations are known to Gaël and the situation gives a conventional meaning. For example, the tutor will have him make a table which clearly prefigures numeration and which resolves this problem, starting with the following round. Gaël already knows perfectly well how to use the table, but part of 
what the tutor plans to talk about is the justification of the table, which will therefore take on an explicit and agreed-upon meaning.

If he had expected Gaël to realize for himself that such a table was needed and to propose one, he would probably have been disappointed: Gaël could perfectly well work the situation out with the notation he used the first time, messy or not. Conditions would have had to be a lot harder (larger number of sides, lots of movements of the pieces, larger numbers) to justify and provoke the invention of an accounting type procedure. The cognitive profit from such a situation would have been minor relative to the amount of energy and motivation it would have swallowed up.

\section{Second try}

The tutor proposes to Gaël that he should decide in advance how many objects to take out of the bag. Gaël pulls out 7 objects and then determines exactly the quantity of elements of each color remaining in the bag by looking at the numbers on the paper and removing from them the objects spread out on the table

The tutor then suggests a "way of writing it that will save time", namely the following table:

[Insert Figure 12] 
-"When you count them all, how many blues are there?" asks the tutor. -"9"

-"Where are you going to write them?"

Gaël indicates the box and completes the whole line, thereby "economizing on the writing”.

From the didactical point of view, this scene is a transitional phase designed to put the decor in place for a new learning situation. The planned new situation is to be a phase of didactical institutionalization. To prepare the way for this game, which is to simulate a known game requiring the participation of the student at a "subordinate "level relative to the "novelties" introduced, the teacher communicates the rules of the new game...coming up. In ordinary class situations, this game never appears except in the form of a very closed exercise in applications.

And Gaël makes no mistake about it: as the amount of didactical interference increases, Gaël passes progressively from his lively, smiling attitude to one which is more serious and more concentrated. Conscientiously he sets to work on the task, but, always polite and even friendly, he enters into his position of student learning under the baton of his teacher. It is time to break this contract, which is comfortable and dangerous for Gaël, and exchange the positions of the tutor and the student. 


\section{The Game of "Liar!"}

They take up the game again, but this time it is the tutor who takes the objects out of the bag, and furthermore he includes a new element in the rules: they are going to play "Liar!" Gaël doesn't know what that one is about, so the tutor explains:

- I am going to take out objects, and when I finish I will say 'There are this many greens, that many blues, etc. (in the bag)', and if I am wrong you say "Liar!" If I succeed in lying, I win, but if you succeed in trapping me when I lie, you win!

They try a first round: the tutor takes out a small bunch and states:

-There are 6 blues in the bag.

At his request, the child writes the number on the table and checks by counting backwards, starting with 10 and counting off the blue objects in sight. He agrees with the number stated.

-"There are 6 reds", the tutor next states.

-"6 reds" repeats Gaël, “6,7,8,9 (he adds in the reds spread on the table): "Liar!"

Gaël says this word with a little bit of concern and a lot of pleasure. He smiles. It took him some audacity, even though he knew that he had the license to do it. Under the fiction of the game, Gaël enters the other role, that of interior interlocutor mentioned earlier. The passage from one position to the other, from declarer to judge, from liar to 
person responsible for the truth...and above all the possibility of passing from one rôle to another offers Gaël the means for a symbolic rupture with his earlier position. This rupture, with respect to knowledge, can be compared to that of the famous Fort-Da game of Freud.

The verification is done and yes! Gaël is right and the tutor has been caught. Note that his "error" had been a trick, and for Gaël the detection of the error has become a game, done in a spirit of complicity and agreement rather than aggression. There is more than one nuance between the classical meaning of an error and the symbolic one that it takes on here. Later on maybe Gaël will do some teasing himself and make up his own "tricks".

They continue in the same way with the other colors, and the child makes no mistakes, but as he goes along he hasn't written on the table the objects removed and the objects remaining. The tutor advises him to recapitulate: for the red ones, the number stated was 6 and Gaël said "Liar!" To that 6 , he had added the 3 on the table, which had confirmed his judgment. But he doesn't know any more what to do to get the 10 reds in all. He has to be helped:

_"How many were there altogether?"

$-10$

- And how many there?" (on the table) $-3$ 
-"So that leaves..."

$-7$

Note also that though Gaël keeps on making his "little mistakes", the tutor is careful not to take him to task for it and contents himself with getting Gaël to fix them. As the situation gets more complex, and as there get to be more and more occasions to examine differences or to carry out subtractions, Gaël develops strategies which serve as the meaning of the operation and uses them with more and more facility. Thus, to check the validity of the statement " $10-3=6$ " he carries out $6+3=9$.

Now Gaël no longer looks, as he did before, defeated in the face of subtraction, with the sort of refusal that seemed to appear in the previous sessions. He now manipulates them more easily, though he is not able to use them in a systematic way every time it's necessary or at least handier. Thus, when he has 10 and 3 he knows that he has to "do 10 - 3" to find what's "left" (the aim of subtraction) but when he had 6 and then 9 and needed 10 the problem seemed totally different to him.

The tutor then has him fill in the line of "take away's", but he gets mixed up and writes 5 yellows instead of 5 greens. The tutor has him correct that before asking him how, if he hadn't corrected it, he could have spotted the error.

The table is as follows: 
[Insert Figure 13]

Gaël does not manage to provide the explanation requested, but that may be due to the fact that he has the complete table in front of him. Possibly if he had had only the column:

\section{[Insert Figure 14]}

he could have come up with the correction. He has to be given the solution.

The verification that we pointed out above is functioning implicitly, but it is not perceived as a fact by Gaël, it is apparently not something he would be able to formulate, and a fortiori he can't use it to convince anybody, even a benevolent and attentive interlocutor.

It is easy to see, thus,

- why the tutor had to propose addition as a means of checking subtraction-Gaël probably would not have invented it 
- why it was all right to propose it, because it was not proposed as an object to be learned. It had a role and meaning which were obvious in the situation, and it had simply been made available to Gaël.

- and how Gaël appropriated this means and integrated it into his procedures. From this point, it may be that creating situations favoring making this explicit will suffice to get Gaël to evoke the relations between addition and subtraction. Situations of that sort assume that one has at least provisionally rejected concrete means of proofrecourse to counting things-and consequently that one operates on symbolic systems.

The tutor sets to work immediately preparing this new phase, making a material separation between two systems: that of the collections which can be physically manipulated and that of the writing used to talk about what happens to the former. This materialization will give the two of them the means to recall this situation later on.

\section{Symbolization by labels}

It's time for a new game: groups of objects are represented by pieces of paper. The tutor puts into one bag pieces of paper which represent the objects that Gaël is putting in the other: for example, he writes " 6 green" on a piece of paper and Gaël puts 6 green objects in the bag. He makes a certain number of pieces of paper this way: 


\section{[Insert figure 15]}

and each one fills his own bag. Then they exchange them, so that Gaël is the one with the bag of papers

_" Can you tell me how many red objects I have in my bag?" the tutor asks. You can't open my bag, but you can open yours"

-" Then I sure can!", replies Gaël, opening his bag with a big smile.

He finds a first piece of paper :

[Insert figure 16]

and says ; "7 reds!"

-’That's all?"

He then checks all the bits of paper and adds up the numbers on all the ones indicating the color red: $7+5+5=17$. 
He writes 17 on the preceding table and then counts the other colors and writes those results up, too:

\author{
[Insert Figure 17]
}

When the tutor asks if he is sure of the results he just got, the child looks hesitant and would really like to check. They re-count together. For the green ones he explains: "6 and 3, 9. And 4...If we have 4, we take away one of them (to add onto the 9) that makes 10 and since we took one away there that makes 3 so that makes 13."

Then the tutor writes the number of objects that he is (theoretically) taking out: 10 of each color, and Gaël unhesitatingly finds the number left of each color.

\title{
4.2 Behavior expected in the course of these situations: uncertainty and knowledge
}

Gaël really dislikes renouncing the charms of uncertainty. To understand how such an attitude can block the acquisition of knowledge and how the situations we propose might operate, it will be useful to look more closely at the relationships that establish themselves between knowledge and uncertainty in a teaching situation. 
Knowledge manifests itself through a decision, or rather through a choice among several decisions, or among several opinions. For a student to be able to put a piece of knowledge into action, he must therefore be offered situations which can have different outcomes depending on the choice he himself makes as a function of his knowledge. The meaning of the knowledge is made up, as we said, of the spread of envisigable outcomes which it makes it possible to reject. If a piece of knowledge permits the elimination of all but one outcome, it permits a sure decision But it can happen that knowledge about a subject lets several outcomes subsist, with perhaps some preferences which could translate into probabilities of choosing each outcome. We will then say that the situation presents the subject with a certain uncertainty, larger or smaller depending on the number of outcomes and their equiprobable character, Learning a piece of knowledge manifests itself by the diminution of the uncertainty in situations in which it is engaged (one can even evaluate the quantity of information represented by a piece of knowledge by the variation it produces in the uncertainty.)

In general, learning happens in a situation, motivated by the desire of the subject to diminish his uncertainty.

Thus one can compare didactical situations to games. The teacher communicates to the student a problem situation which puts on the scene the objects in question, and gives what corresponds to the rules: that is, the means he is allowed to use to obtain all possible states of the game. He fixes certain objectives, that is, some results which are to be obtained following the rules with, explicitly or implicitly, a reward. To be sure, the 
character of these didactical games can vary a lot depending on the subjects and the types of pedagogy chosen. In particular, on whether the teacher is assumed to be supposed to communicate the strategies for resolution from the start or the student is supposed to produce them as a means of adapting himself. But the bottom line is that at some point the activity of the student will consist, in the face of a problem situation which presents him with a certain uncertainty, of reducing it by choosing a solution: the student is not doing mathematics unless he is solving problems.

For all that, it would be false to believe that the acceptance of the rules and the reduction of uncertainty is the only manifestation of knowledge and acquisition. Information can augment the subject's uncertainties by showing him choices he hadn't thought about. What he learns closes off some questions, but opens others.

The search for new situations, for questions or for new rules - which increase uncertainty - is a tendancy inverse and complementary to the one just discussed. The production of questions and the production of answers are two very different manifestations of knowledge and its genesis. They respond to each other "dialectically" from one moment to the next in the epistomelogical subject, from one notion to another in the organization of his knowledge and finally between knowledge and the subject in the course of his development. The search for new problems responds to different motivations depending whether this dialectic is aimed at adapting the world to the subject and the subject to the world (Piaget's assimilation) or aimed at the internal transformation 
of the subject, for his organization, his consitency and his own ergonomy (Piaget's accomodation).

To understand the profound unity of this quest for knowledge, let us examine from the point of view of the student the function to which it responds.

To start with, the absence of uncertainty cannot be a stable state. In a way, the subject defines himself, exists in his own eyes with respect to a milieu, by the modifications he can produce in it. A milieu which gives him no opportunity for action-that is, for decision or for choice-in effect denies his existence as an autonomous subject. This is in particular the case in closed situations. Inversely, but for the same reason, a purely random choice is not an expression of the subject and also fails to give him existence One can thus imagine that the subject is always in search of situations which are either relatively open, which he can reduce by exercising the creation of knowledge and of his power of decision and action, or relatively closed and such that he can open them by the consideration of new variables and new rules.

Psychoanalysis gives a deeper analysis of this phenomenon and permits the comprehension of the relations of knowledge considered as a symbolic object with the motivations of the subject. 


\section{CONCLUSIONS OF THE STUDY OF THE CASE OF GAËL}

There remain four more sessions in which the tutor continues to fight to introduce more and more difficulties and put Gaël under the obligation of surmounting them. Every relationship is governed by the same principle. The progress is not spectacular, but it seems, after the fact, as if this fourth session had been decisive.

The relationship which developed with the tutor and a certain awakening of awareness of difficulties to avoid launched a new attitude for Gaël.

Follow-up reports indicated that the child integrated well into his class and rapidly filled in his mathematical gaps.

The general aims of the intervention were as follows:

a) At first to establish a climate of confidence: an agreeable dual relationship which nonetheless took account of the difficulties at issue.

b) At the second stage, to make use of this relationship to propose to Gaël some didactical situations in which knowledge was not to be found in either the discourse or the desire of the teacher, but rather in a relationship with the milieu. These interactions 
needed to be motivated by the desire of the child himself, and to lead him to take on decisions specific to the knowledge to be mastered: experiment, decide, search,...

c) At the third stage, by new ruptures with the didactical contract, the issue was to get him to give a "price" to truth, and possibly to prefer it to the comfort of a consensus: to choose, for instance, to verify a result despite the discomfort of acknowledging an error. It was obviously not a matter of producing a moralizing lecture on the subject, but of obtaining these behaviors in an effective way. We tried to get him in the habit of defining himself, recognizing himself and pleasing himself as a constructor of knowledge and the person responsible for his convictions, faced with the facts or faced with others around him. We wanted him to experience mathematical activities not as "the discovery of his mistakes", "the recognition of failure", "the revelation of his sins" or more drastically as "the look into his parents' bedroom" but as an exercise in equilibration, liberation and foundation of "myself".

The reader should not be led astray by these formulations. It is not a matter of psychotherapy but of didactique, that is, of specific activities intentionally organized with a view to the acquisition of specific knowledge. But it is necessary to be aware of the psychological dimension of these interventions,

\section{CONCLUSIONS OF THE CLINICAL APPROACH}


Gaël was one of nine cases studied between 1976 and 1983. Some succeeded, some failed and some were partial successes. But no characteristics common to all of the cases turned up, except perhaps for the importance of their psycho-affective problems.

The tutor caught in a difficult relationship and the observers surprised by massive failures of the student have a tendency to concentrate their attention on the characteristics of the child and not on the conditions of the situations confronting them.

\section{A-didactical situations}

In our first approach, we have nonetheless two opposite types of reaction which struck us as important. These reactions can only be observed when the child has accepted an activity for which he takes responsibility and where he can know on his own whether he has succeeded or failed. In acknowledging that the results do not conform to their predictions, certain children turn pale and worry; they read this result as a personal failure and look discouraged and guilty. Even if they get bravely back to work, their behavior shows that the situation is having an internal impact.

Others, on the other hand, seem to wake up suddenly: something unexpected and interesting is happening; personal failure is gotten past and minimized in favor of curiosity and an opening towards the exterior. 
These two opposite ways of reacting to learning situations (that is, where the relationship with the adult is not directly an issue) are relatively stable in the subjects, in time and the material covered by different problems. The children in selective failure whom we encountered all belonged to the first category.

\section{Didactical situations}

The second remark comes from contrasting the behaviors of Gaël and Cyrille (with whom we had a partial success) in their relations with the tutor. Both wanted to avoid a relationship they felt to be conflictual. But they did it with diametrically opposed strategies. The obligation to take responsibility to produce one's own answer to a question proposed by an adult is a painful experience for children who are failing. There are at least two manners of avoiding it:

One consists of taking it excessively seriously, dramatizing it as much as possible in a mode which we qualify metaphorically as "obsessional" (Cyrille's type). The other, on the other hand, consists of evading it to the largest degree possible by simulating more or less adroitly a minimal participation (Gaël's type).

Every question puts students of the first type into a worrisome situation, or even a dangerous one, and sends them back to the original situation. To escape from this grave aggression, they must close the question immediately, no matter how, if necessary knowing nothing about it at all. Leaning on the didactical contract, they refuse to accept 
a question unless they already have the solution in hand. They require the teacher to transform solutions into algorithms, to state criteria for the use of an algorithm and reassuring signs that they are on the right track... the assurance that by memorizing everything that has been said in class they can immediately respond to this horrible situation. And the more they learn and the more good answers they have available, the less chance they have of finding the right one.

For the others, nothing needs worrying about, nothing is serious, everything is theater. In the collective phases they enter into the game, answering with the others, taking risks - the teacher is convinced that these are wide awake students with a good understanding. They may even answer correctly at the moment, but if they are personally interrogated, in writing, for instance, they don't know it, haven't learned it, haven't hung on, they aren't concerned, haven't stashed away any of it. They are agreeable and make no trouble, but they are not there in person, and in the end they learn nothing.

The one and the other, each in his own way avoids confronting the learning situation.

The former lean heavily on the management of the didactical contract and tend rapidly to petrify it. The latter are far harder to spot in the classroom. The teacher doesn't notice until too late that these "intelligent" and wide awake students have failed their first composition, then their second...Incomprehensibly, they know nothing. 
Here are the provisional conclusions which we were able to pull out of this work as of 1980:

\section{THE DIDACTICAL CONTRACT}

In the course of a session whose objective is to teach a student a specific piece of knowledge (a didactical situation) the student interprets the situation presented to him, the questions asked him, the information given him, and the constraints imposed on him as a function of whatever it is that the teacher reproduces, consciously or not, in a repetitive way in his teaching practice. We are particularly interested in whatever amongst these habits is specific to the knowledge being taught: we give the name "didactica l contract" to the set of (specific) behaviors of the teacher which are expected by the student and the set of behaviors of the student which are expected by the teacher.

Present in this question, this "contract" rules the relations of teacher and student an the subject of projects, objectives, decisions, actions and didactical evaluations. It is the "contract" that specifies the reciprocal positions of the participants on the subject of the task, and which specifies the deep meaning of the action under way, of the formulation or of the explanations furnished: what do we need to know? How are we going to tell if we have succeeded? What are we supposed to do if we haven't succeeded? What should we have known to succeed? What are we supposed to say? What else could we have done? what would have been a mistake? What are we supposed to learn? How 
can we learn it? How can we remember it?, etc. It is the "contract" which explicitly fixes the role of knowledge, of learning, of memory, etc.

It is through the rule of decoding didactical activity that scholastic learning passes. One can think that at each instant the activities in a process depend on the meaning he gives to the situation proposed him, and that this meaning depends heavily on the result of the repeated actions of the didactical contract.

The didactical contract thus presents itself as the trace left by the habitual requirements of the teacher (requirements more or less clearly perceived) about a particular situation. The articulation between the habitual or permanent and what is specific to the knowledge aimed at may be better or worse; certain didactical contracts favor the specific functioning of the knowledge to be acquired, others not; certain children read (or don't) the didactical intentions of the teacher and have (or don't) the possibility of pulling out a favorable learning situation.

Might it not be the case that certain didactical contracts prevent certain children from entering into the process of learning?

The causes of failure should then be sought for in the relationship of the student to knowing and in the didactical situations, and not in his aptitudes or in his permanent general characteristics. 
These contracts reveal the idea which teachers and students have of the functioning of mathematics (of its creation, of its use,...) In choosing a didactical situation (that is, a problem situation, objectives for the student, information to give, objectives for the teacher, etc.) to teach a certain piece of knowledge, the teacher produces, whether he wishes or not, an image of the real situations (historical, cultural,...) in which this knowledge functions (was discovered, is used...) which is often quit distorted. It is the circumstances in which the knowledge is used which give it its meaning. Thus a piece of mathematical knowledge does not have the same meaning for a student and for a mathematician. We give the name "didactica l transposition" to the passage from one to the other.

The theory of didactical situations has as its objective to furnish the means of controlling these didactical transpositions. Didactical transposition depends fundamentally on the conceptions the teachers have about mathematical thought. In their teaching activities, teachers are thus obligated to use in a more or less explicit way a sort of theory of knowledge, of the epistemology of mathematics. These conceptions, used strictly professionally, are generally not of a scientific character (nor even consistent), even though locally they are the traces of more or less recent theories. We give the name of "mathematical scholarly thought" to these pseudo-theories.

The teacher teaches this "philosophy" along with the mathematics and since it is not a good description of the appropriation of knowledge, might it explain certain failures? 
A good example of such errors is to be found in the book of Mme. JaulinMannoni, Le Pourquoi en Mathématiques ("The Why in Mathematics") The first part is a very interesting theory of comprehension containing a lot of good ideas. The second presents cases of re-education-laudable effort-but it is not possible to see, for example, how such a discourse attempts to adapt itself in the case of Nadine to a perfect conditioning.

Always in the work of the last three years we have prepared the way for a study of these new hypotheses taking into account the set of these interactions and of these systems, and using theoretical studies of didactical situations and processes.

\section{By way of a conclusion}

In the observations which we have just reported, we have-like most researchers before us - started off with a profile of the child and the personal factors leading to failure, or connected with its effects, this failure being considered nearly always as a pathological phenomenon attached to child.

This conception corresponds very well to the strongest of the three modes of responding to failure : 
1. in the first, the parents react to the worries caused by the difficulties of their children with pressure on the child himself: injunctions, diverse sanctions, special courses, medico-psycho-pedagogical examinations, reeducation,... In the same manner, teachers are led to reduce the excessive insufficiencies by teaching tactics chosen for short term objectives which tend to impose on the child an itinerary which is transparently controlled. The pressure is all the greater if the child can give evidence that he can succeed in other subjects. But focusing on the student is perhaps as vain an enterprise as analyzing the water leaking from a hole in a bucket to see how it differs from the water left in the bucket.

2. Focusing on the scholastic institution as the executor of the teaching contract, on teachers'pedagogical methods, on their training...constitutes the second mode. We have shown the interest we take in it.

3. The third mode consists of focusing on the contract itself (why teach so much-or so little-mathematics, why use mathematics as a selection criterion, why a very short selection etc.)

Each of these three modes of response is supported by hypotheses on different causes of failure in mathematics, but very few are accompanied by a usable method of research.

I have wondered for a long time whether these hypotheses on the instrumental origin of certain difficulties in calculation might not be complacently welcomed principally because they justify certain interventions expected by the parents and 
probably useful to the children (for other reasons) but lucrative for others. Certainly astonishing are the persistence and periodic return of thundering but manifestly false or excessive declarations imputing to the schools responsibility for phenomena for which the entire of society in general is notoriously responsible.

No one form of scholastic difficulty seems to provoke so many passionate reactions, nor to sustain so many prejudgments as failure in mathematics.

Curiously, amongst a mass of publications of opinions, the scarcity of objective works is striking, as if the complexity of the task, or the forces resisting the work had inhibited all scientific research.

It is true that the systems whose functioning or dysfunctioning may play a role in this phenomenon are numerous, and their interactions complex: the child, the parents, the teachers, the school, society, the discipline can be implicated in the course of very diverse approaches: cognitive, psychological or even psychoanalytical, pedagogical or sociological. The economic rewards of these relations are sometimes large and have contributed to the development of a tangle of subjective value judgments such as to bewilder the observer.

Although this complexity can stimulate the imagination of innovators wanting to help children in difficulty or of polemicists, it can legitimately discourage the researcher 
who may fear the sterility of a too restrictive hypothesis or the nasty surprises of a terrain which is prey to ideology.

We hope nonetheless that the current research will soon permit a little orientation of the debate. 


\section{Bibliography}

1. Chauvet, Le Bars. Le Léon. - Pédagogie moderne de la mathématique et dyscalculie. Mémoire d'orthophonistes. Bordeaux, 1973.

2. Etude de la détection des enfants en difficultés électives en mathématiques en vue d'analyses statistiques. - Mémoires d'orthophonie dirigés par G. Brousseau, institut de recherches sur l'enseignement des mathématiques. Université Bordeaux 1 et Centre de phono-audiologie de Bordeaux 2.

1976, tome 1 : Moras F., Molia C. - Etude des échecs en mathématiques à travers quelques articles relatifs à la dyscalculie.

1977, tome 1 : Berrocq-Irigoin M. Dupuch M.-A. Fruchard C. - Elaboration d'un questionnaire

1977, tome 2 : Berrocq-Irigoin M. Dupuch M.-A. Fruchard C. - Monographie d'un enfant en difficultés

1978, tome 1 : Dugué C. - Etude critique de la détection dans le cadre de l'institution scolaire.

1978, tome 2 : Trolonge D. - Comparaison des questionnaires aux maitres avec les acquisitions scolaires.

1978, tome 3 : Château F. Analyse comparée et étude longitudinale des questionnaires. 1978, tome 4 : Amirault C. Chéret M.. - Monographie de deux enfants en difficultés 
1979, tome 1 : Mora M. Monographie de deux enfants en difficultés.

1979, tome 2 : Bonais M. - Détection des enfants en échec électif au CM1

1980， Leygue R. M. Monographies de trois enfants en difficulté.

1983, Sevaux P. A propos d'un soutien d'enfant en mathématique : échec électif ou dyscalculie?

3. Dugas et Guillarme. - introduction à l'étude des difficultés en calcul chez l'entant, Revue de neuro-psychiatrie infantile, $1970, \mathrm{n}^{\circ} 1-2$.

4. Laffon. - Vocabulaire de psychopédagogie et de psychiatrie de l'enfant Paris. P. U.F., 1963,

5. Gibello B. - Dysharmonies cognitives et dyscalculies. Revue de neuropsychiatrie infantile, $1973, \mathrm{n}^{\circ} 6$.

6. Hasaerts Van Gertruyden - La dyscalculie chez l'enfant, Diagnostic différentiel Revue de neuropsychiatrie infantile, 1975 n $^{\circ} 10-11$

7. Bourrel M.-J. Echec en calcul à travers 570 dossiers. Place des troubles relationnels au père. Mémoire pour le CES de Psychiatrie.

8. Deveyle P. Frisson L. et Gauthier J. - Recherche d'une concordance entre l'échec en mathématiques et les résultats du bilan orthophonique (dyscalculie). Mémoire pour le C. C. d'orthophonie, Lyon 1973

9. Eyraguibel J. Brousseau G. Appareillage de mesure automatique des stratégies d'apprentissage. Application à un jeu logique : les tours d'Hanoï in Mesures régulation automatisme " $\mathrm{n}^{\circ} 1$ Bordeaux, 1978

10. Gabinski P. - Etude sur les situations d'acquisition des modèles récursifs et l'appropriation du concept de récurrence. I.R.E.M, de Bordeaux 


\section{Jaulin-Mannoni F.- Le pourquoi en mathématiques. E.S.F-, 1978.}

\footnotetext{
${ }^{\mathrm{i}}$ This text presents the description and final study of four of the eight sessions which made it possible for Gaël to continue successfully in his school mathematics. Itis based on a text written in 1981 by Guy Brousseau and Jacques Pérès. The transcriptions by Michèle Berrocq-Irrigoin of the eight sessions and those of their "analysis on the spot" were put out in mimeographed form by the IREM for the use of researchers, but the last four have never been studied and written up in the way in which the first four were. The experiment was carried out in 1977. It furnished the foundational material for an entire portion of the theory of situations. A number of questions raised by this experiment have led to a number of concpts. In a periodof rapid evolution it was not possible to write up the conclusions which at the time seemed incomplete, and the study of these concepts and of the inital relationships by numerous researchers made their publication unnecessary.

${ }^{\text {ii }}$ Center for Observation and Research in Mathematics Education

iii G: There are more wooden beads than red beads!"

T: "Why?"

G: "Because the wooden beads are all of them (pointing to the whole collection) and the red ones are just some of them!"

iv Success with the inclusion test supposes necessarily that the child has reached the operational stage and can very easily master the relation of commutativity.

${ }^{v}$ Pagnol ; Marcel, Topaze, Fasquelle éditeur, 1930

${ }^{\mathrm{vi}}$ In the Theory of Situations meaning, in particular that of subtraction, consists of

1. the set of situations which are resolved by a "subtraction"

2. the set of solution procedures for these situations (in particular those which are based on "primitive" repertoires, and for which subtraction is a sort of re-writing)

3. the set of cultural means and of relations developed to "explain" subtraction. That is, the knowledge (considered to be) used to "constrain" a student and which simulates his (supposed) comprehension of subtraction.

${ }^{\text {vii }}$ Following this work, the list of subtraction strategies and their domains of optimal efficiency as a function of various variables was studied by I. Katembera in his Third Cycle Thesis (directed by G. Brousseau.)
} 